\title{
Telomerase Activity and Telomere Length in Primary and Metastatic Tumors from Pediatric Bone Cancer Patients
}

\author{
ELENA SOTILLO-PIÑEIRO, LUIS SIERRASESÚMAGA, AND ANA PATIÑO-GARCÍA \\ Fels Institute for Cancer Research and Molecular Biology [E.S.-P.], Temple University, Philadelphia, PA \\ 19140, U.S.A.; and Laboratory of Pediatrics [L.S., A.P.-G.], Department of Pediatrics, "Los Castaños" \\ Building, University Clinic and University of Navarra, E-31080 Pamplona, Spain.
}

\begin{abstract}
The presence of telomerase activity has been analyzed in almost all tumor types and tumor-derived cell lines. However, there are very few studies that focus on the presence of telomerase activity in bone tumors, and most of them report analysis on very few samples or bone-derived cell lines. The objective of this study was to analyze the telomere length and telomerase activity in primary tumors and metastatic lesions from pediatric osteosarcoma and Ewing's sarcoma patients. The presence of telomerase activity was analyzed by the telomeric repeat amplification protocol assay, and the telomere length was measured by Southern blot. Results were related to survival and clinical outcome. Telomerase activity was detected in $85 \%$ of the bone tumor metastases (100\% Ewing's sarcomas and 75\% osteosarcomas) but only in $12 \%$ of the primary tumors $(11.1 \%$ osteosarcomas and $12.5 \%$ Ewing's sarcomas). Bone tumor tissues with telomerase activity had mean telomere lengths $3 \mathrm{~kb}$ shorter than those with no detectable telomerase activity $(p=0.041)$. The
\end{abstract}

\section{ABSTRACT}

presence of telomerase activity was associated with survival ( $p=$ 0.009 ), and longer event-free survival periods were found in patients who lacked telomerase activity compared with those who had detectable telomerase activity levels in their tumor tissues $(p=0.037)$. The presence of longer telomeres in primary pediatric bone tumors than in metastases could be indicative of alternative mechanisms of lengthening of telomeres for their telomere maintenance rather than telomerase activity. Nevertheless, the activation of telomerase seems to be a crucial step in the malignant progression and acquisition of invasive capability of bone tumors. (Pediatr Res 55: 231-235, 2004)
Abbreviations
ALT, alternative lengthening of telomeres
TRAP, telomeric repeat amplification protocol
TRF, telomeric restriction fragment

Human telomeres are composed of (TTAGGG)n tandem repeats, and they protect eukaryotic chromosomes, preventing their degradation, fusion, and recombination $(1,2)$. With each cell division, there is a telomere loss of 50 to $200 \mathrm{bp}$ as a result of the inability of the DNA-polymerase to completely replicate the 3 ' end of the lagging strand (the "end-replication" problem) (3), and this progressive loss of noncoding genetic material leads to cell senescence when a critical telomere length is reached. It has been postulated that this growth arrest is mediated by the TP53 or RB1 tumor suppressor gene pathways in response to DNA damage $(4,5)$.

Telomerase is a ribonucleoprotein composed of three subunits (6-8) that compensates for telomere loss by adding telomeric repeats onto chromosomal ends, thus lengthening the

Received November 18, 2002; accepted June 29, 2003.

Correspondence: Ana Patiño-García, Laboratory of Pediatrics, "Los Castaños" Building, E-31080 Pamplona, Spain; e-mail: apatigar@unav.es

Supported by RTIC Cáncer C10/03 (FIS, Spanish Ministry of Health).

DOI: 10.1203/01.PDR.0000102455.36737.3C proliferative cell life (9). Telomerase activity directly depends on its catalytic subunit (hTERT) $(10,11)$, and it has been detected in $50 \%$ to $100 \%$ of all tumor types and in $70 \%$ of cells immortalized in vitro but not in most normal somatic tissues $(12,13)$. Some telomerase-negative cell lines immortalized in vitro possess very long and heterogeneous telomeres as the result of alternative mechanisms for lengthening telomeres (ALT) (14). Some of these telomerasenegative cell lines are the osteosarcoma-derived cell lines Saos2, U-2 OS, and G-292 (15).

Osteosarcoma is the most frequent bone tumor diagnosed during childhood and adolescence, and 10 to $15 \%$ of the patients present distant metastases at diagnosis $(90 \%$ lung, $10 \%$ other bones). Ewing's sarcoma is the second pediatric bone tumor in frequency; most of them are diagnosed during the second decade of life, and 15 to $20 \%$ of the patients have metastases at diagnosis (50\% lung, $25 \%$ other bones, $25 \%$ bone marrow) (16).

There are scarce and controversial data concerning the telomere maintenance mechanisms of pediatric bone tumors, and 
the objective of this study was to analyze the presence of telomerase activity and the telomeric restriction fragment (TRF) lengths in primary and metastatic tissue samples from Spanish Ewing's sarcoma and pediatric osteosarcoma patients.

\section{METHODS}

Samples and patients. We have included samples from 17 osteosarcoma and 13 Ewing's sarcoma pediatric patients who were treated and followed at the Department of Pediatrics of the University Clinic of Navarra (Spain) by standard protocols $(17,18)$. The investigation was approved by the Ethics Committee of the University Hospital, and informed consent was obtained from all of the participants or their parents. Tissues were classified according to their origin in primary tumors (biopsies; 12 osteosarcoma and 13 Ewing's sarcoma samples) and metastases (10 from osteosarcomas and seven from Ewing's sarcomas) and frozen at $-80^{\circ} \mathrm{C}$ until use.

Telomeric repeat amplification protocol assay. Protein extraction by CHAPS buffer (3-[(3-Cholamidopropyl)dimethylammonio]-1-propanesulfonate) followed by the telomeric repeat amplification protocol (TRAP) assay was performed as described previously $(19,20)$. In brief, 50-100 $\mathrm{mg}$ of each tissue specimen was thawed on ice and homogenized in 300 $\mu \mathrm{L}$ of lysis buffer [0.5\% CHAPS, $10 \mathrm{mM}$ of Tris- $\mathrm{HCl}(\mathrm{pH} 7.5)$, $1 \mathrm{mM}$ of $\mathrm{MgCl}_{2}, 1 \mathrm{mM}$ of EGTA, $5 \mathrm{mM}$ of 2-mercaptoethanol, $10 \%$ glycerol]. After a 30 -min incubation on ice, the lysate was centrifuged at $16,000 \times g$ and the supernatant was recovered and used for protein quantification.

The protein concentration of lysates was measured using the MicroBCA Kit (Pierce, Rockford, IL, U.S.A.). The assay uses PCR to amplify the products of the telomerase-catalyzed extension of the oligonucleotide primer telomerase substrate. To exclude interference with the TRAP assay by telomerase or PCR inhibitors, we included two different protein concentrations $(1 \mu \mathrm{g} / \mu \mathrm{L}$ and $5 \mu \mathrm{g} / \mu \mathrm{L})$ for each sample and a third reaction with RNAse Out (GibcoBRL, Prat del Llobregat, Barcelona).

The PCR procedure was performed in a GeneAmp PCR system 2400 (Perkin-Elmer, Wellesley, MA, U.S.A.) with an initial step of 2 min at $92^{\circ} \mathrm{C}$ followed by 25 cycles of $95^{\circ} \mathrm{C}$ for $30 \mathrm{~s}, 50^{\circ} \mathrm{C}$ for $30 \mathrm{~s}$, and $72^{\circ} \mathrm{C}$ for $30 \mathrm{~s}$. The PCR amplification products were resolved by $8 \%$ denaturing $(7 \mathrm{M}$ of urea) polyacrylamide gels (19:1) for $1 \mathrm{~h}$ at $20 \mathrm{~mA}$. Gels were exposed and analyzed in a phosphoimager (BioRad, Hercules, CA, U.S.A.).

TRF length analysis. TRF length was measured in 25 primary tumors and 17 metastatic tissues and in paired peripheral blood samples by Southern blotting, using the telomere complementary probe (TTAGGG) ${ }_{4}(21)$. In brief, $5 \mu \mathrm{g}$ of genomic DNA was digested with HinfI (New England Biolabs, Beverly, MA, U.S.A.) and subjected to electrophoresis in $0.8 \%$ agarose gels at $35 \mathrm{~V}$ for $22 \mathrm{~h}$. Gels were then denatured and neutralized. DNA was transferred to a nylon membrane, and blots were hybridized with 1 to $1.5 \times 10^{6} \mathrm{cpm} / \mathrm{mL}$ of the $\left[\gamma_{-}{ }^{32} \mathrm{P}\right] \mathrm{dATP}$ end-labeled $\left[\gamma_{-}{ }^{32} \mathrm{P}-(\mathrm{TTAGGG})_{4}\right]$ telomeric probe at $50^{\circ} \mathrm{C}$ for $16 \mathrm{~h}$, followed by three consecutive washes with $4 \times$ salt sodium citrate and $0.5 \%$ SDS solution at $50^{\circ} \mathrm{C}$ for 40 ,
30 , and $15 \mathrm{~min}$. The telomere length was estimated by comparison with a molecular weight marker and analyzed with the Quantity One 4.0.3 phosphoimager software (BioRad).

The mean TRF length was calculated using the following formula: Mean $=\Sigma\left(\mathrm{OD}_{\mathrm{i}}\right) / \Sigma\left(\mathrm{OD}_{\mathrm{i}} / \mathrm{L}_{\mathrm{i}}\right)$, where $\mathrm{OD}$ is the intensity of hybridization signal and $\mathrm{L}$ is the length, in $\mathrm{Kb}$, at the gel point i (22).

Statistical analysis. The quantitative variables were compared by the $t$ test (upon fulfillment of the normality criteria), and the presence of telomerase activity in the different tumor tissue types was compared by $\chi^{2}$ with Yates modification for small numbers if needed. The differences were considered statistically significant when their associated probability was $p$ $\leq 0.05$. The statistical analysis was performed using the Statistical Package for the Social Sciences program, version 10.0 (SPSS, Chicago, IL, U.S.A.).

\section{RESULTS}

Telomerase activity. In the TRAP assay, the presence of telomerase activity yields a 6-bp ladder as a result of the synthesis of the telomeric hexanucleotide. Each sample was assayed at two different protein concentrations $(1 \mu \mathrm{g} / \mu \mathrm{L}$ and 5 $\mu \mathrm{g} / \mu \mathrm{L})$ and with RNAse as a negative control.

The 30 tissue samples analyzed were classified according to their origin in primary tumors and metastases and according to their diagnosis in osteosarcomas and Ewing's sarcomas. The presence of telomerase activity in metastases was statistically increased compared with primary tumors, both in osteosarcomas and in Ewing's sarcomas (Table 1). All of the Ewing's sarcoma metastases showed detectable telomerase activity compared with $12.5 \%$ of the primary tumors. In the case of the osteosarcoma tissues, $75 \%$ of metastases had detectable activity, compared with $11.1 \%$ of the primary tumors (Table 1 ). The primary tumors that showed telomerase activity, one osteosarcoma and one Ewing's sarcoma, corresponded to patients who presented metastases at the time of diagnosis, both dying in $<2$ years after diagnosis.

The presence of telomerase activity in tumor tissues was associated with survival, and $75 \%$ of the patients who showed activity in their tissues died, whereas $76.5 \%$ of the patients who lacked telomerase activity are still alive ( $p=0.009$; Table 2$)$. We detected significantly longer event-free survival periods in patients who lacked telomerase activity compared with those who had detectable telomerase levels in their tumor tissues $(p$

Table 1. Telomerase activity in tissue samples from pediatric bone tumors in relationship to tissue origin

\begin{tabular}{clcc}
\hline Tumor type & Sample type & $\begin{array}{c}\text { No. with TA } \\
+ \text { No. analyzed }\end{array}$ & Probability* \\
\hline Osteosarcoma & Primary tumor & $1 / 9$ & \\
& metastases & $6 / 8$ & \\
Ewing's sarcoma & Primary tumor & $1 / 8$ & \\
& metastases & & \\
& metastases & $5 / 5$ & 0.001 \\
Total & Primary tumor & $2 / 17$ & \\
& metastases & $11 / 13$ & \\
\hline
\end{tabular}

TA, telomerase activity.

$* \chi^{2}$ test with continuity correction. 
Table 2. Telomerase activity in tumor samples from osteosarcoma and Ewing's sarcoma patients in relationship to survival

\begin{tabular}{lllll}
\hline \multicolumn{1}{c}{ Tumor type } & \multicolumn{1}{c}{ Survival } & TA + & TA- & Probability* \\
\hline Osteosarcoma & Alive $(n=11)$ & 2 & 9 & \\
& Dead $(n=6)$ & 5 & 1 & \\
Ewing's sarcoma & Alive $(n=5)$ & 2 & 3 & \\
\multirow{5}{*}{ Total } & Dead $(n=6)$ & 4 & 2 & \\
& Alive $(n=16)$ & $4(23.5 \%)$ & $12(76.5 \%)$ & $p=0.009$ \\
& Dead $(n=12)$ & $9(75 \%)$ & $3(25 \%)$ & \\
\hline
\end{tabular}

* $\chi^{2}$ test with continuity correction.

$=0.037)$. That the development of metastasis is an independent poor prognostic factor in pediatric bone tumors strongly suggests that the association between mortality and telomerase activity is related to the presence of this activity being detected almost exclusively in metastatic lesions.

TRF length. Hybridization with the telomeric probe generates a smear that covers all of the telomeric lengths within the sample. In general, metastatic tissues had statistically shorter TRFs than primary tumors $(p=0.026)$. Several of the primary tumors had a mean TRF length longer than $15 \mathrm{~kb}$, whereas some of the metastases did not reach $5 \mathrm{~kb}$.

Telomere length was compared in 25 primary tumors and 17 metastases to peripheral blood samples from the same patients by a $t$ test for paired samples (Fig. 1). Primary tumors had mean TRF lengths $(11.4 \mathrm{~kb})$ significantly longer $(p=0.032)$ than paired peripheral blood samples $(9.7 \mathrm{~kb})$, but no differences were found when comparing metastases $(8.8 \mathrm{~kb})$ with peripheral blood samples $(p=0.146)$.

Bone tumor tissues with telomerase activity had mean TRF lengths $3 \mathrm{~kb}$ shorter than those with no detectable telomerase activity $(p=0.041)$. Nevertheless, the detection of telomerase activity almost exclusively in metastases does not allow us to determine whether the differences in TRF length are due to the sample type (metastases or primary tumors) or to the presence of telomerase activity.

\section{DISCUSSION}

Telomerase activity has been detected in 85 to $90 \%$ of all tumor types analyzed to date, but primary pediatric bone tumors seem to develop mechanisms other than telomerase to maintain their telomere length during the initial steps of their carcinogenesis; nevertheless, they need to activate telomerase for progression and full malignization. The presence of telomerase activity in $87 \%$ of osteosarcoma and $100 \%$ of Ewing's sarcoma metastatic samples compared with $11 \%$ of osteosarcoma and $12.5 \%$ of Ewing's sarcoma primary tumors agrees with the results obtained by other authors (23-25). Nevertheless, there are several other reports in the literature that describe presence of telomerase activity in 85 to $100 \%$ of primary osteosarcomas $(26,27)$. In addition, Sangiorgi et al. (27) detected an association between high level of telomerase activity and better outcome in the seven osteosarcomas analyzed, which contrasts both with our findings and with their own in other bone and soft tissue tumors. In our opinion, the discrepancies between different reports may be due to the low number of patients included, which makes it very difficult to establish

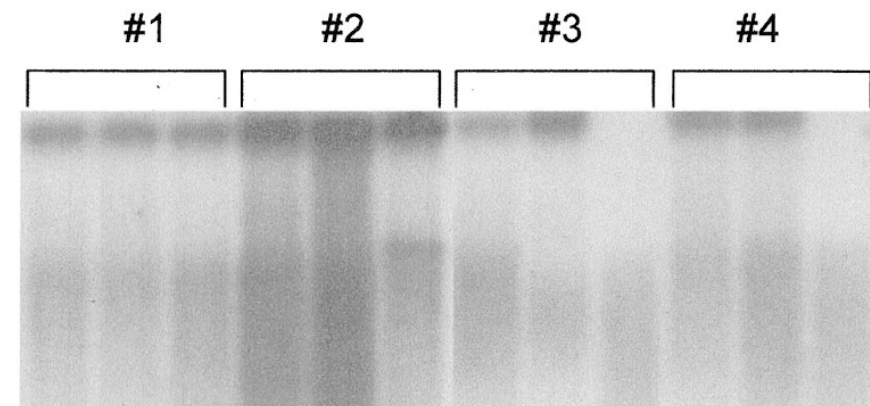

\section{$\begin{array}{llllllllllll}\mathbf{B} & \mathbf{R} & \mathbf{M} & \mathbf{B} & \mathbf{M} & \mathbf{R} & \mathbf{B} & \mathbf{R} & \mathbf{M} & \mathbf{B} & \mathbf{R} & \mathbf{M}\end{array}$}

Figure 1. Southern blot showing the TRF lengths of samples from four pediatric osteosarcomas. Each three lanes correspond to different samples from the same patient. $\mathrm{B}$, blood; $\mathrm{R}$, tumoral resection; $\mathrm{M}$, metastasis.

relationships with clinical parameters, as well as the inclusion of heterogeneous osteosarcoma patients and even adults in the same analysis.

The difference between the level of telomerase activity detected in primary and metastatic tumor tissues could indicate that the activation of telomerase is a hallmark of the full malignant phenotype of pediatric bone tumors. The involvement of telomerase in the malignization process could be explained by an evolution in the mechanism of telomere maintenance during carcinogenesis, from ALT mechanisms to the activation of telomerase, or by an earlier activation of telomerase.

Several publications support the idea that telomerase is activated in the later steps of carcinogenesis (28-30). In view of the putative role for telomerase on carcinogenesis proposed by other authors for other tumor types (30), one could hypothesize that alterations in tumor suppressor genes, such as TP53 or $R B 1$, or in genes involved in the telomeric complex, such as TRF1 and TRF2, could favor the ALT mechanisms (Fig. 2, pathway 1).

The tumor cell lines that use ALT mechanisms are characterized by the presence of heterogeneous TRF lengths. It has 


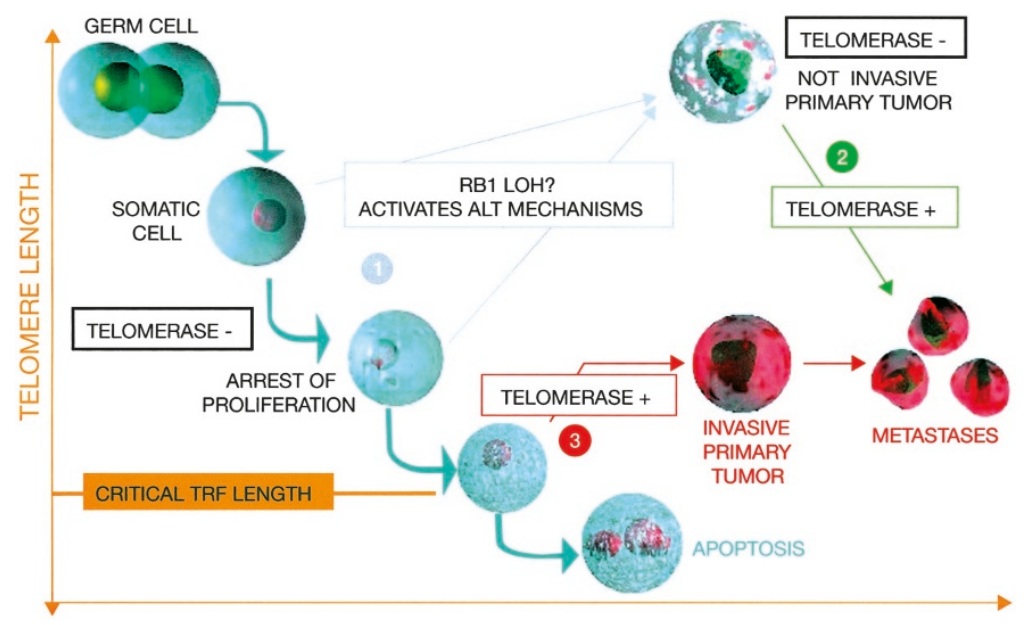

Figure 2. Models for bone tumor progression. (Pathway 1) Activation of ALT mechanisms as a result of loss of heterozygosity at RB1 or mutations in telomeric proteins. (Pathway 2) Later telomerase activation in several cells as a result of the accumulation of mutations in regulator genes or chromosomal aberrations. (Pathway 3) Earlier activation of telomerase arising from critical telomere shortening in bone tumor progression. Reprinted from Kim et al. (30), with permission from Elsevier.

been demonstrated that the ALT mechanisms can coexist with telomerase activity in cell cultures and tumors $(31,32)$. The presence of extremely short TRFs in some chromosomes is enough for the activation of telomerase, which could protect the cell from chromosome fusion, terminal deletions, and other chromosomal aberrations (33). Once telomerase has replaced the lost telomeric repetitions, the cell can keep on proliferating until it achieves the invasive and metastatic capability (Fig. 2, pathway 2). Nevertheless, the presence of telomerase activity in preinvasive benign tissues in several carcinomas (prostate, liver) $(34,35)$ indicates that early activation of telomerase also exists and that telomerase cooperates in the malignant progression process.

Another possibility is that inside the tumor mass, a scarce number of cells could escape from senescence and crisis by the activation of telomerase when their telomeres become critically shortened. Those cells could then go on to generate the metastatic lesions (Fig. 2, pathway 3). From the results obtained in this study, it could be inferred that ALT mechanisms are less effective than telomerase in the malignant progression, which gives justification to the fact that telomerase-positive cells are responsible for the appearance of metastases.

The existence of these primary telomerase-positive cells could be detected by in situ hybridization but, because of the scarce amount of tissue, this verification could not be done in our study. Nevertheless, the presence of smears in the low molecular weight region of the blots may indicate the presence of such cells in the primary tumors that were not detectable in the background of the more abundant cells with longer TRFs.

This second hypothesis seems to be the most logical for bone tumors. If this hypothesis is right, then pediatric bone tumors would be generated by ALT mechanisms as a result of any genetic alteration that induces this pathway for the maintenance of the telomere length. In a recent study, overexpression of cyclin D1 increased the proliferative life of normal keratinocytes, and, when the TP53 gene was also inactivated, the authors obtained immortal cells with very heterogeneous TRF, which lacked telomerase activity (36). In fact, a recent report by Ulaner et al. (25) concluded that ALT is the predominant mechanism for telomere maintenance in osteosarcomas and that this may be due to the lower cell turnover that is present in mesenchymal tissues compared with carcinomas, which may be associated with stronger physiologic repression of telomerase expression (37).

Maybe one of those mechanisms or one of the genetic alterations that induce the activation of ALT mechanisms in osteosarcomas involves the RB1 gene, which has been associated with longer TRF in retinoblastoma and in immortal cell lines (15). In our series of tumor tissue samples, we found that all of the samples with loss of heterozygosity at RB1 (4 of 21) (38) had TRF $5 \mathrm{~kb}$ longer than those with normal RB1 (data not shown).

The difference in TRF length between telomerase-negative and -positive samples $(p=0.041)$ suggests that telomerase is activated when the telomere length becomes critical, to ensure the proliferation levels required for immortalization. However, it could also indicate that ALT mechanisms generate longer telomeres than telomerase. Data to support this theory have been published by other authors mainly in tumor-derived cell lines that lack telomerase activity as well as those derived from osteosarcomas $(39,40)$.

There was no detectable difference in the TRF length or telomerase activity levels between osteosarcomas and Ewing's sarcomas. This indicates that both tumor types could be using the same mechanisms for telomere maintenance.

The cytogenetic alterations responsible for the development of 95\% Ewing's sarcomas are well known, but the carcinogenesis of osteosarcomas requires further investigation because, to date, neither genetic nor cytogenetic alterations have been described that are present in the vast majority of these tumors.

The detection of telomerase activity in almost all of the metastatic tissues analyzed makes telomerase an attractive target for the discovery of new anticancer agents focused on the arrest of bone tumor progression. In fact, several antitelomerase or telomere-interacting molecules are already being widely investigated (41). 
Acknowledgments. We are indebted to Dr. María Antonia Blasco for kind assistance and help in the optimization of the techniques included in this article. We thank Renée M. Marshall for manuscript editing.

\section{REFERENCES}

1. Biessmann H, Mason JM 1997 Telomere maintenance without telomerase. Chromosoma 106:63-69

2. Blackburn EH 1991 Structure and function of telomeres. Nature 350:569-573

3. Levy MZ, Allsopp RC, Futcher AB, Greider CW, Harley CB 1992 Telomere end-replication problem and cell aging. J Mol Biol 225:951-960

4. Reddel RR 1998 Genes involved in the control of cellular proliferative potential. Ann NY Acad Sci 854:8-19

5. Artandi SE, De Pinho RA 2000 A critical role for telomeres in suppressing and facilitating carcinogenesis. Curr Opin Genet Dev 10:39-46

6. Ramakrishnan S, Sharma HW, Farris AD, Kaufman KM, Collins K, Pruijn GJ, van Venrooij WJ, Marfin ML, Narayanan R 1997 Characterization of human telomerase complex. Proc Natl Acad Sci USA 94:10075-10079

7. Feng J, Funk WD, Wang SS, Weinrich SL, Avilion AA, Chiu CP, Adams RR, Chan E, Chang E, Allsopp RC, Yu J, Le S, West MD, Harley CB, Andrews WH, Greider CW, Villeponteau B 1995 The RNA component of human telomerase. Science 269:1236-1241

8. Nakamura TM, Morin GB, Chapman KB, Weinrich SL, Andrews WH, Lingner J, Harley CB, Cech TR 1997 Telomerase catalytic subunit homologs from fission yeast and human. Science 277:955-959

9. Greider CW, Blackburn EH 1985 Identification of a specific telomere terminal transferase activity in Tetrahymena extracts. Cell 43:405-413

10. Ramakrishnan S, Eppenberger U, Mueller H, Shinkai Y, Narayanan R 1998 Expression profile of the putative catalytic subunit of the telomerase gene. Cancer Res 58:622-625

11. Yan P, Saraga EP, Bouzourene H, Bosman FT, Benhattar J 2001 Expression of telomerase genes correlates with telomerase activity in human colorectal carcinogenesis. J Pathol 193:21-26

12. Shay JW, Bacchetti S 1997 A survey of telomerase activity in human cancer. Eur J Cancer 33:787-791

13. Kim NW, Piatyszek MA, Prowse KR, Harley CB, West MD, Ho PL, Coviello GM, Wright WE, Weinrich SL, Shay JW 1994 Specific association of human telomerase activity with immortal cells and cancer. Science 266:2011-2015

14. Bryan TM, Englezou A, Dalla-Poza L, Dunham MA, Reddel RR 1997 Evidence for an alternative mechanism for maintaining telomere length in human tumors and tumor-derived cell lines. Nat Med 3:1271-1274

15. Gupta J, Han LP, Wang P, Gallie BL, Bacchetti S, Schwartz HS, Dahir GA, Butle MG 1996 Development of retinoblastoma in the absence of telomerase activity. J Natl Cancer Inst 88:1152-1157

16. Arndt CA, Crist WM 1999 Common musculoskeletal tumors of childhood and adolescence. N Engl J Med 341:342-352

17. Meyers PA, Heller G, Healey J, Huvos A, Lane J, Marcove R, Applewhite A, Vlamis V, Rosen G 1992 Chemotherapy for nonmetastatic osteogenic sarcoma: the Memorial Sloan-Kettering experience. J Clin Oncol 10:5-15

18. Rosen G, Juergens H, Caparros B, Nirenberg A, Huvos AG, Marcove RC 1981 Combination chemotherapy (T-6) in the multidisciplinary treatment of Ewing's sarcoma. Natl Cancer Inst Monogr 56:289-299

19. Kim NW, Wu F 1997 Advances in quantification and characterization of telomerase activity by the telomeric repeat amplification protocol (TRAP). Nucleic Acids Res 25:2595-2597

20. Wright WE, Shay JW, Piatyszek MA 1995 Modifications of a telomeric repeat amplification protocol (TRAP) result in increased reliability, linearity and sensitivity. Nucleic Acids Res 23:3794-3795
21. Iwama H, Ohyashiki K, Ohyashiki JH, Hayashi S, Yahata N, Ando K, Toyama K, Hoshika A, Takasaki M, Mori M, Shay JW 1998 Telomeric length and telomerase activity vary with age in peripheral blood cells obtained from normal individuals. Hum Genet 102:397-402

22. Mehle C, Ljungberg B, Roos G 1994 Telomere shortening in renal cell carcinoma. Cancer Res 54:236-241

23. Aue G, Muralidhar B, Schwartz HS, Butler MG 1998 Telomerase activity in skeletal sarcomas. Ann Surg Oncol 5:627-634

24. Scheel C, Schaefer KL, Jauch A, Keller M, Wai D, Brinkschmidt C, van Valen F, Boecker W, Dockhorn-Dworniczak B, Poremba C 2001 Alternative lengthening of telomeres is associated with chromosomal instability in osteosarcomas. Oncogene 20:3835-3844

25. Ulaner GA, Huang HY, Otero J, Zhao Z, Ben-Porat L, Satagopan JM, Gorlick R, Meyers P, Healey JH, Huvos AG, Hoffman AR, Ladanyi M 2003 Absence of a telomere maintenance mechanism as a favorable prognostic factor in patients with osteosarcoma. Cancer Res 63:1759-1763

26. Aogi K, Woodman A, Urquidi V, Mangham DC, Tarin D, Goodison S 2000 Telomerase activity in soft-tissue and bone sarcomas. Clin Cancer Res 6:4776-4781

27. Sangiorgi L, Gobbi GA, Lucarelli E, Sartorio SM, Mordenti M, Ghedini I, Maini V, Scrimieri F, Reggiani M, Bertoja AZ, Benassi MS, Picci P 2001 Presence of telomerase activity in different musculoskeletal tumor histotypes and correlation with aggressiveness. Int J Cancer 95:156-161

28. Counter CM, Gupta J, Harley CB, Leber B, Bacchetti S 1995 Telomerase activity in normal leukocytes and in hematologic malignancies. Blood 85:2315-2320

29. Blasco MA, Rizen M, Greider CW, Hanahan D 1996 Differential regulation of telomerase activity and telomerase RNA during multi-stage tumorigenesis. Nat Genet 12:200-204

30. Kim NW, Hruszkewycz AM 2001 Telomerase activity modulation in the prevention of prostate cancer. Urology 57:148-153

31. Cerone MA, Londono-Vallejo JA, Bacchetti S 2001 Telomere maintenance by telomerase and by recombination can coexist in human cells. Hum Mol Genet 10:1945-1952

32. Perrem K, Colgin LM, Neumann AA, Yeager TR, Reddel RR 2001 Coexistence of alternative lengthening of telomeres and telomerase in hTERT-transfected GM847 cells. Mol Cell Biol 21:3862-3875

33. Hackett JA, Feldser DM, Greider CW 2001 Telomere dysfunction increases mutation rate and genomic instability. Cell 106:275-286

34. Sommerfeld HJ, Meeker AK, Piatyszek MA, Bova GS, Shay JW, Coffey DS 1996 Telomerase activity: a prevalent marker of malignant human prostate tissue. Cancer Res 56:218-222

35. Hytiroglou P, Kotoula V, Thung SN, Tsokos M, Fiel MI, Papadimitriou CS 1998 Telomerase activity in precancerous hepatic nodules. Cancer 82:1831-1838

36. Opitz OG, Suliman Y, Hahn WC, Harada H, Blum HE, Rustgi AK 2001 Cyclin D1 overexpression and p53 inactivation immortalize primary oral keratinocytes by a telomerase-independent mechanism. J Clin Invest 108:725-732

37. Henson JD, Neumann AA, Yeager TR, Reddel RR 2002 Alternative lengthening of telomeres in mammalian cells. Oncogene 21:598-610

38. Patiño-García A, Piñeiro ES, Díez MZ, Iturriagagoitia LG, Klüssmann FA, Ariznabarreta SL 2003 Genetic and epigenetic alterations of the cell cycle regulators and tumor suppressor genes in pediatric osteosarcomas. J Pediatr Hematol Oncol 25:362367

39. Bryan TM, Englezou A, Gupta J, Bacchetti S, Reddel RR 1995 Telomere elongation in immortal human cells without detectable telomerase activity. EMBO J 14:42404248

40. Grobelny JV, Kulp-McEliece M, Broccoli D 2001 Effects of reconstitution of telomerase activity on telomere maintenance by the alternative lengthening of telomeres (ALT) pathway. Hum Mol Genet 10:1953-1961

41. Shay JW, Wright WE 2002 Telomerase: a target for cancer therapeutics. Cancer Cell $2: 257-265$ 